\title{
An Intervention Program for Mothers Regarding Dependency Level of their Children with Cerebral Palsy
}

\author{
Awatef. A. Afifi (1), Seham G.Ragheb2, Hemat. A. Elsayied(2), Suheir. A. Mekhemar \\ (2), Hamed.A.El-Khayat (3),
}

Community Health Nursing department, Faculty of nursing,Ain shams university-Pediatric department Faculty of Medicine, Ain shams university(3).

\begin{abstract}
Cerebral palsy (CP) is a permanent disorder of posture and movement resulting from brain damage occurring in the baby or young child. Cerebral palsy is a term used to describe a collection of disorders caused by abnormal brain development or damage to the brain that occurs around the time of birth or early in life. This study aimed to evaluate the intervention program for mothers regarding dependency level of their children with CP. Setting the current data was Neurology out- patient clinic at pediatric hospital Ain Shams University. Sample, The study was conducted on one hundred and twenty four mothers who have been selected for the program pre, post, and after 3 month later. Tools: Two tools for data collection, tool (I) An interviewing questionnaire sheet (II) Child's activities of daily living assessment. Results of this study showed that the main age of mothers was $37.6 \pm 0.6$ years and noticeable improvement in the mothers' knowledge and practice and dependency level of their children were detected after implementation of intervention program compared to pre and 3 month after program implementation. So, this study concluded that intervention program affected positively regarding caring of mothers regarding dependency level of their children with cerebral palsywhich indicate justification of the study hypotheses. this study recommended that Educational sessions should be provided for mothers of cerebral palsy children about care of their children, as well as, community resources from whom they may seek assistance and support to fulfill with all dependency level of their CP child.
\end{abstract}

Key words: Cerebral palsy, independency level, practice

\section{Introduction}

Cerebral palsy $(\mathbf{C P})$ is a permanent disorder of posture and movement resulting from brain damage occurring in the baby or young child. Cerebral palsy is a term used to describe a collection of disorders caused by abnormal brain development or damage to the brain that occurs around the time of birth or early in life (Sawatzky,2015).
Cerebral palsy is a general

term for a group of permanent movement problems that do not get worse over time. They cause physical disability, mainly in the areas of body movement. There may also be problems with sensation, depth perception, and communication ability. Difficulty with cognition and epilepsy are found in about one-third of cases. There are subtypes including a type characterized by spasticity, a type characterized by poor coordination, and 
types which feature both symptoms and neither (Gulanick\&Myers,2016

CP may be caused by damage to the parts of the brain that control movement, this damage generally occurs during the fetal or perinatal period, particularly in premature infants. Common prenatal causes are separation of the placenta, bleeding, maternal infection and nutritional deficiencies mean while perinatal causes are anoxia immediately before, during and after birth, asphyxia, and birth trauma about $10 \%$ to $20 \%$ occur after birth. Common postnatal causes are head trauma, infection and cerebrovascular accident (Zarei \&Gilanian,2015).

Cerebral palsy is the most common motor disability in childhood. Populationbased studies from around the world report prevalence estimates of CP ranging from 1.5 to more than 4 per 1,000 live births or children of a defined age range. In Egypt, there are more than 3.4 million handicapped child. The prevalence of $\mathrm{CP}$ in Egypt ranges from 2 to 3 per 1000 live births, this rate increases to $40-100$ per 1000 live births among babies born very early or with very low birth-weight The estimation of children with CP in Egypt is about 76.117,46 (WHO,2011)

Mothers of the children with $\mathrm{CP}$ are vital member of the professional team; the most important role of them is the lifelong interest in the commitment to their children. They may feel helpless and confused, so that they need information, intervention and support to rehabilitation program and learn to manage the practical difficulties, which can disrupt the developing relationship with their children (Winder,2013).

Mothers as caregivers may not fulfill their roles due to lack of understanding to the physical, psychological, emotional, social needs of their child. They like to help themselves and sometimes form own help groups and arrange friendships and events, etc. In general they receive little support from relatives, friends and neighbors (Stenvenson, 2016).

Intervention program may be defined as an organized method of ensuring that people have knowledge and skills for a specific purpose and that they acquired the necessary knowledge to perform the duties of the job. The knowledge may require increased affective, motor, or cognitive skills. It is expected that acquiring new skills will increase productively or create a better product (Shahim, 2014).

The Community health nurse is expected to fill all of her role as care provider, advocate, teacher and Counselor, observer, organizer and decision-maker. Management of children with CP includes referral of suspected cases, family education about diagnosis, family support, financial aid, nutritional management, movement and mobility management, communication management and advocacy (MC-Court, 2015).

Significance of the study:-

Cerebral palsy is damage to the brain that cannot currently be fixed treatment and therapy help manage effects on the body. The injury \&damage to the brain is permanent. The brain doesn't heal as other parts of the body .Because of this, the CP itself will not change for better or worse during a person's life time. It is a blanket for several disorders that affect normal, healthy movement (Martin, 2016). 
Aim of the study:

The aim of this study was to evaluate the intervention program for mothers regarding dependency level of their children with $\mathrm{CP}$ through, assessing level of mothers' knowledge and practices related to care for their children with cerebral palsy and the dependency level of the children, Planning, Developing, implementig of educational intervention program, and evaluate the outcome of the intervention program on the level of knowledge, practice related to care and dependency level of the children.

\section{Research Hypotheses}

1-Mother's level of knowledge and practice related to their children care will be increasing significantly post program.

2-Intervention program will improve some factors might affect on level of mother's knowledge and practices also, dependency level of their children.

\section{Subject and Methods:}

\section{Research design:}

Intervention design will be conducted for this study.

\section{Setting:}

The study conducted at the Neurology out- patient clinic at pediatric hospital Ain Shams University

\section{Subjects:}

A purposive sample of 124 mothers accompanying their children. in Neurology out- patient clinic at pediatric hospital Ain Shams University.

\section{Tools of data collection:-}

1-First tool: - An interviewing questionnaire divided into four part:-

Part one:- socio-demographic data of mothers and their children as Age, level of education, occupation Bailey (2011).

Part two:-Child health assessment ( using medical record) weight,hight ,medical history and investigations. Scoring: Mild: less than 3 problems, Moderate: 3 - 5 problems, Sever: more than 5 problems. These was developed by the researcher based on comprehensive reviewing and recent literature Deon and Gaebler-Spira (2014).

Part three:-It was designed to assess level of mothers' knowledge about CP (pre, post \&follow up).Scoring: incorrect answer (0 -49\%) (Poor), correct but incomplete answer (50-69\%)Average and correct answe r (70-100\%) (Good).

Part four: It includes assessment of mothers 'practical knowledge regarding their children with $\mathrm{CP}$ (pre, post \& follow up). Scoring: Not done: (0 -49\%), Done but incomplete: (50-69\%), Done correctly: (70 -100\%) Alber man, (2013).

2-Second tool: - Child's activities of daily living (ADL) assessment. Scoring: $1-12=$ dependent, $13-23$ $=$ Assisted (independent with assistant (partial dependent), $24-36=$ Independent (Shaw, 2010). Preparatory phase:

It includes reviewing of literature related to the program design and the theoretical knowledge of the various aspects of the intervention program using books, articles, magazines, and an 
internet to develop the tools for data collection.

Pilot study: It was carried out in outpatient clinic for 12 mothers

(10\% of study sample). Field work: Data collection was started and completed within 10 months from May 2015 until end of October 2015 then after 3 months done follow up test for one month at February 2016.

\section{Ethical consideration:}

The researcher approval obtained from the ethical committee before starting the study. At the initial interview a synopsis about the nature, purpose and benefits of the study, was given for each subject. Statistical Design:

Data collection obtained, they were organized, categorized, tabulated and statistically analyzed to evaluate the difference between pre, post and 3 months after the program as regards the various parameters. Data were presented in tables and figures using the statistical package for social science (SPSS). Statistical significant associations were assessed using percentage (\%), mean, standard deviation, chi square, t-test, $\mathrm{p}$ value and $r$ test.

\section{Results:}

The present study results revealed that the main age of mothers (studies group) was $37.6 \pm 0.6$ years, more than one third of them $(37.1 \%)$ was illiterate, More than quarter of them (77.4\%) were housewife, more than half of mothers $(61.3 \%)$ were living in crowded housing condition, more than three quarter of them $(82.3 \%)$ had insufficient income ,more than half of mothers $(51.6 \%)$ had natal causes.
Study results revealed that the mean age of children was $4.5 \pm 0.5$, nearly two third of them $(63.7 \%)$ were boys, more than one third of them (34.7\%)ranked as the third in their families, the majority $(58.1 \%)$ were spastic type, majority had mild \&moderate $\mathrm{CP}(58.1 \%),(30.6 \%)$ respectively.

Regarding of child health assessment the present study results revealed that the majority $(66 \%)$ were under weight, more than three quarter (79\%) of children were abnormal investigations. Regarding systemic child health problems, this study showed more than half of children were mild condition.

The present study results revealed that, statistically highly significant difference regarding total level of mothers' knowledge pre/ post program implementation in relation to most of items $\left(\mathrm{X}^{2}=162.8\right)$; pre/3 month after the program implementation $\left(\mathrm{X}^{2}=128.1\right)$ and insignificant difference between post/after 3 month later of program implementation $\left(X^{2}=6.4\right)$.

There was noticeable improvement in the mothers' knowledg detected after the implementation of the intervention program which dropped slightly 3 month after program implementation.

There was statistically highly significant difference regarding total level of mothers' practice pre/ post program implementation in relation to most of items $(\mathrm{T}=17.1)$; pre/3 month after the program implementation ( $\mathrm{T}=128.1)$; and insignificant difference between post/after 3 month later of program implementation $(\mathrm{T}=0.11)$.

Regarding total level of mothers' practice pre/ post and 3 month after program implementation this study showed also noticeable improvement in 
the mothers' practice detected after the implementation of the intervention program.

There was statistically highly significant difference regarding total level of children dependency pre/ post program implementation in relation to daily activities $\left.\left(X^{2}=156.6\right)\right)$; pre/3 month after the program implementation $\left(\mathrm{X}^{2}=158.1\right)$ and insignificant difference between post/after 3 month later of program implementation $\left(\mathrm{X}^{2}=0.47\right)$.

There was noticeable improvement in most items in children' dependency as reported from mothers after the implementation of the intervention program.

The present study results revealed that, statistically significant positive relation was detected between total mothers' knowledge and their total practice pre, post and follow up.
There was a statistically significant positive relation between age of children and their level of dependency pre/ post and follow up.

The study revealed statistically significant positive relations between gender of children and their level of dependency pre and post intervention program.

There was a statistically significant positive relation between associated problems of children and their level of dependency pre and post intervention program.

The study revealed that, there was a statistically significant positive relation between family income and dependency of children pre and post intervention program.

Part 1: Sociodemographic characteristics and child health problems (table 1 -2)

Table (1) Distribution of mothers according to their Sociodemographic Characteristics $\quad(\mathrm{n}=124)$

\begin{tabular}{|c|c|c|}
\hline Items & No & $\%$ \\
\hline \multicolumn{3}{|l|}{ Age : } \\
\hline $18-<30$ & 24 & 19.4 \\
\hline $30-<45$ & 68 & 54.8 \\
\hline 45 or more & 32 & 25.8 \\
\hline Mean \pm SD & $37.6 \pm 0.6$ & \\
\hline \multicolumn{3}{|l|}{ Mothers' education:- } \\
\hline Illiterate & 46 & 37.1 \\
\hline Read and Wright & 32 & 25.8 \\
\hline Basic education & 27 & 21.8 \\
\hline High education & 19 & 15.3 \\
\hline \multicolumn{3}{|l|}{ Mothers' Occupation:- } \\
\hline Working & 28 & 22.6 \\
\hline Not working & 96 & 77.4 \\
\hline \multicolumn{3}{|l|}{ Crowding Index:- } \\
\hline$>3$ Crowded & 76 & 61.3 \\
\hline$<3$ not crowded & 48 & 38.7 \\
\hline \multicolumn{3}{|l|}{ Income / month:- } \\
\hline Sufficient & 22 & 17.7 \\
\hline insufficient & 102 & 82.3 \\
\hline
\end{tabular}


Table (2): Distribution of children according to their sociodemographic characteristics and associated problems $\quad(n=124)$

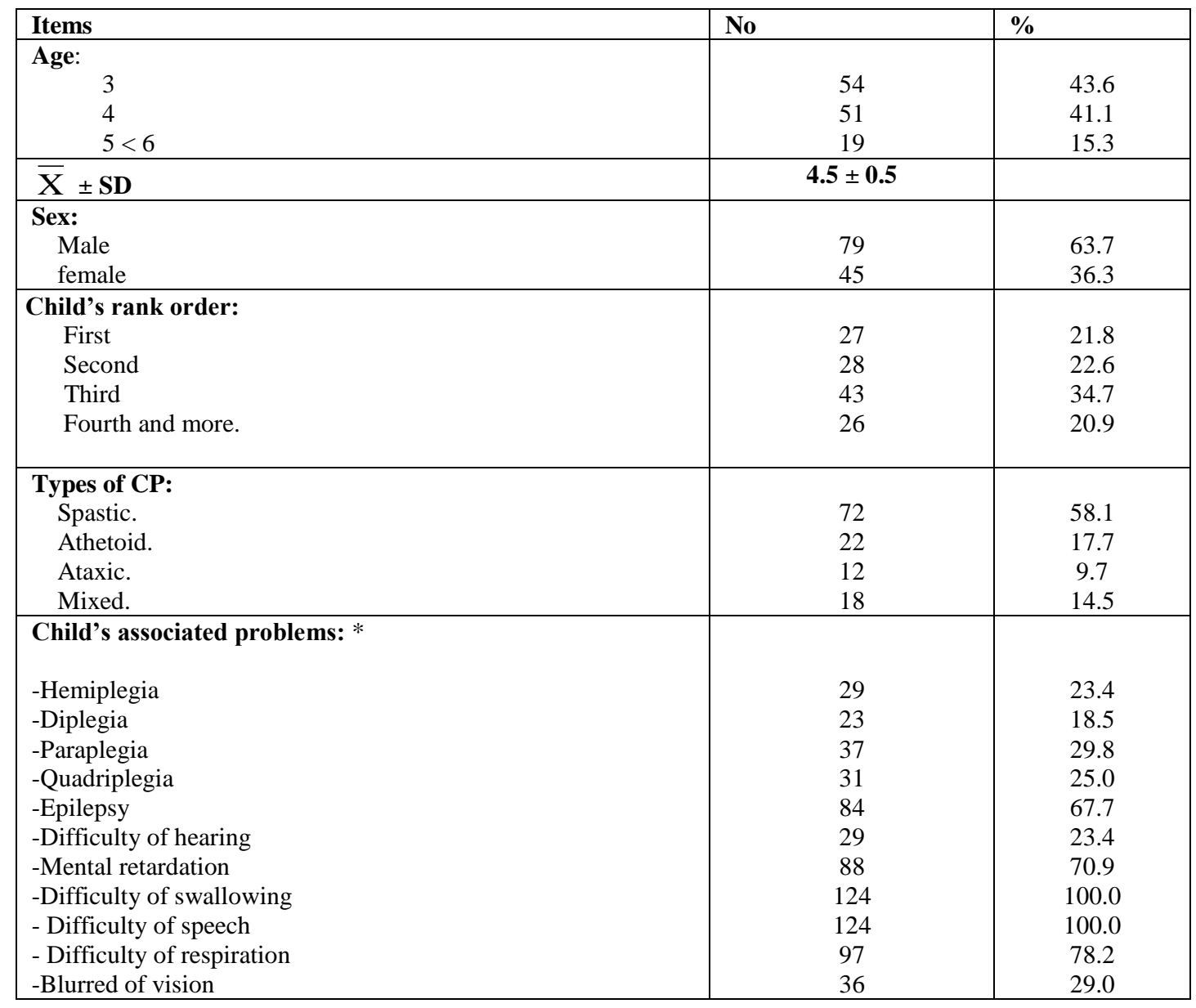


Figure (1): Total level of mothers' knowledge toward pre / post and follow-up intervention program.

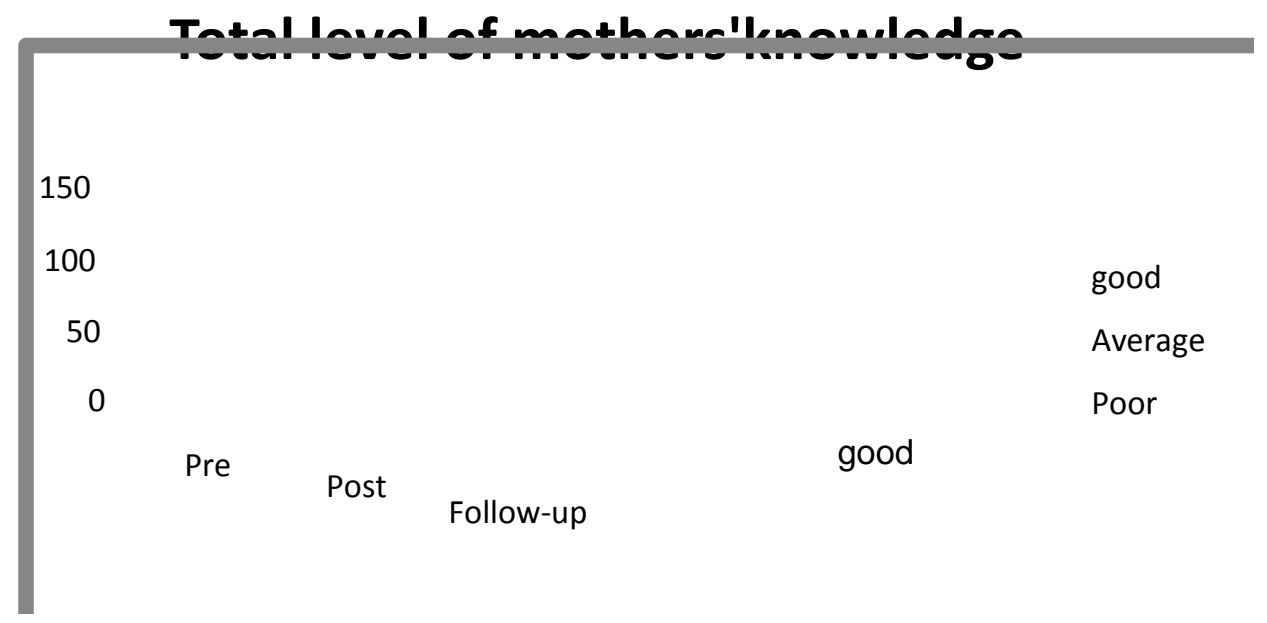

Figure (2): Total level of mothers' practices toward pre / post and followup intervention program.

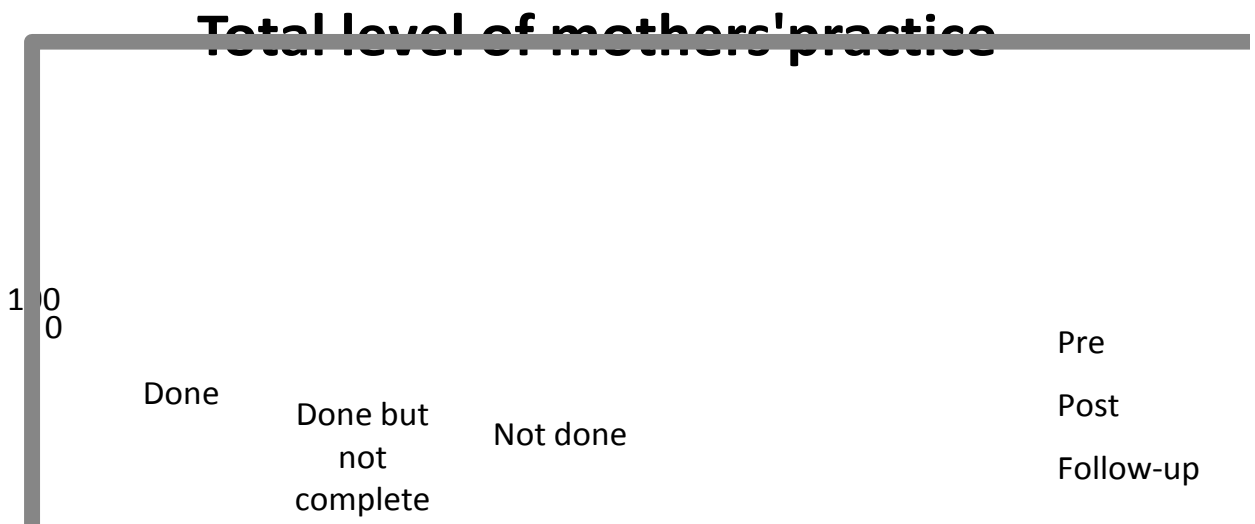


Table (3) Correlation between mothers' knowledge and their practice $(\mathbf{n}=124)$

\begin{tabular}{|c|c|c|c|c|c|}
\hline \multirow[t]{2}{*}{ Knowledge } & \multicolumn{5}{|l|}{ practice } \\
\hline & Poor & Average & Good & Total N0. & r.Test \\
\hline Pre:- & No $=86$ & No $=23$ & No $=15$ & \multirow[b]{2}{*}{99} & \multirow{4}{*}{$0.90 * *$} \\
\hline Poor & 82 & 13 & 4 & & \\
\hline Average & 3 & 6 & 5 & 14 & \\
\hline Good & 1 & 4 & 6 & 11 & \\
\hline Post :- & No $=11$ & No $=14$ & No $=99$ & \multirow{4}{*}{$\begin{array}{c}4 \\
16 \\
104\end{array}$} & \multirow{4}{*}{$0.93 * *$} \\
\hline Poor & 3 & 1 & - & & \\
\hline Average & 7 & 4 & 5 & & \\
\hline Good & 1 & 9 & 94 & & \\
\hline Follow up:- & No $=9$ & No $=17$ & No $=98$ & \multirow[b]{2}{*}{14} & \multirow{4}{*}{$0.92 * *$} \\
\hline Poor & 6 & 8 & - & & \\
\hline Average & 3 & 5 & 10 & 18 & \\
\hline Good & - & 4 & 88 & 92 & \\
\hline
\end{tabular}

** High sig. / P $<0.001$

Table (4): Correlation between Associated problems of children \& their mothers' total level of knowledge pre $\&$ post intervention program no $=124$.

\begin{tabular}{|c|c|c|c|c|c|c|c|c|}
\hline \multirow{3}{*}{ Total level of knowledge } & \multicolumn{6}{|c|}{ Associated problems } & \multirow{3}{*}{$\begin{array}{c}\text { Total no. } \\
\text { (124) }\end{array}$} & \multirow{3}{*}{ r- test } \\
\hline & \multicolumn{2}{|c|}{$\begin{array}{c}\text { Mild } \\
\mathrm{No}=72\end{array}$} & \multicolumn{2}{|c|}{$\begin{array}{c}\text { Moderate } \\
\text { No }=38\end{array}$} & \multicolumn{2}{|c|}{$\begin{array}{c}\text { Sever } \\
\text { No }=14\end{array}$} & & \\
\hline & No & $\%$ & No & $\%$ & No & $\%$ & & \\
\hline Pre & 57 & 79.2 & 32 & 84.2 & 10 & 71.4 & 99 & \\
\hline Poor & 7 & 9.7 & 4 & 10.5 & 3 & 21.4 & 14 & $0.80 * *$ \\
\hline $\begin{array}{l}\text { Average } \\
\text { Good }\end{array}$ & 8 & 11.1 & 2 & 5.3 & 1 & 7.2 & 11 & \\
\hline Post & & & & & & & & \\
\hline Poor & - & - & 1 & 2.6 & 3 & 21.4 & 4 & \\
\hline Average & 9 & 12.5 & 6 & 15.8 & 1 & 7.2 & 16 & $0.89 * *$ \\
\hline Good & 63 & 87.5 & 31 & 81.6 & 10 & 71.4 & 104 & \\
\hline
\end{tabular}

** High sig. / $\mathrm{P}<0.001$ 
Table (5): Correlation between Associated problems of children \& their mothers' total level of Practice pre \& post intervention program $n=124$.

\begin{tabular}{|c|c|c|c|c|c|c|c|c|}
\hline \multirow{3}{*}{ Total level of Practice } & \multicolumn{6}{|c|}{ Associated problems } & \multirow{3}{*}{$\begin{array}{c}\text { Total } \\
\text { no. } \\
\text { (124) }\end{array}$} & \multirow{3}{*}{ r- test } \\
\hline & \multicolumn{2}{|c|}{$\begin{array}{c}\text { Mild } \\
\mathrm{No}=72\end{array}$} & \multicolumn{2}{|c|}{$\begin{array}{c}\text { Moderate } \\
\text { No }=38\end{array}$} & \multicolumn{2}{|c|}{$\begin{array}{c}\text { Sever } \\
\text { No }=14\end{array}$} & & \\
\hline & No & $\%$ & No & $\%$ & No & $\%$ & & \\
\hline Pre & 56 & 77.8 & 29 & 76.3 & 1 & 7.1 & 86 & \\
\hline Not done & 9 & 12.5 & 5 & 13.2 & 9 & 64.3 & 23 & $0.77 * *$ \\
\hline $\begin{array}{l}\text { Done but incomplete } \\
\text { Done correctly }\end{array}$ & 7 & 9.7 & 4 & 10.5 & 4 & 28.6 & 15 & \\
\hline Post & 2 & 2.8 & 7 & 18.4 & 2 & 14.3 & 11 & \\
\hline Not done & 10 & 13.9 & 1 & 2.6 & 3 & 21.4 & 14 & $0.81 * *$ \\
\hline $\begin{array}{l}\text { Done but incomplete Done } \\
\text { correctly }\end{array}$ & 60 & 83.3 & 30 & 79.0 & 9 & 64.3 & 99 & \\
\hline
\end{tabular}

** High sig. / P $<0.001$

Table (1) revealed that there was the mean age of mothers were 37.6 \pm 0.6 .Regarding mothers' education there was $37.1 \%$ were illiterate, while $15.3 \%$ were high education. Mothers' occupation, was $77.4 \%$ were not working. Crowding index, it was noticed the 61.3\% was crowded and income was $82.3 \%$ had insufficient income. Table (2): This table showed that $43.6 \%$ of children aged 3 years with mean age $4.5 \pm 0.5 .63 .7 \%$ of children were males. The child's rank order was $44.4 \%$, were first and second while these third and fourth were $34.7 \%$ and $20.9 \%$ respectively. Related to types of CP, $58.1 \%$ were spastic type while 9.7\% were ataxic type. Table (3) This table illustrates that there was a significant positive correlation ( $\mathrm{r}$-Test $=0.90,0.93,0.93)$ between mothers' knowledge and their practice pre, post and follow up finding. Table (4): Show that there was a significantly positive correlation ( $\mathrm{r}$-Test $=0.80,0.89$ ) between associated problems of children \& their mothers' total level of knowledge. Table (5): Show that there was a significantly correlation ( $r$-Test $=$ $0.77,0.81$ ) between associated problems of children \&their mothers' total level of Practice pre\& post intervention program. Figure (1) illustrated that the total level of mothers' knowledge after implementation program was good than befor, and follow up $(83.9 \%$, $8.9 \% \& 74.2 \%$ respectively). Figure(2) illustrated that the total level of mothers' practices after implementation program which reveal more done than before program, and follow up program implementation( $99 \%, 15 \% . \& 98 \%)$.

\section{Discussion}

Cerebral palsy $(\mathrm{CP})$ is an abnormality of motor function and postural tone that is acquired at an early age, even before birth. Signs and symptoms of cerebral palsy usually show in the first year of life. The aim of this study was to evaluate the intervention program for mothers regarding dependency level of their children with CP through assessing level of mothers' knowledge and practices related to care for their children with cerebral palsy and the dependency level of the children, Planning, Developing and implementing of educational intervention program, and evaluate the outcome of the intervention program on the level of knowledge, practice related to care and dependency level of the children. 


\section{First :-Mothers' characteristics of the studied sample}

One hundred and twenty four mothers caring of children with $\mathrm{CP}$ were included in the present study; their main age was $37.6 \pm 0.6$ years. (Adam et al,2010) mentioned that the mothers should be in suitable age to be able to assume responsible appropriately toward children because young mothers are usually unprepared psychologically for parenthood. More than one third of them was illiterate .while basic education represented more than one fifth. The minority of them was high education (Klingels, et al., 2011), highlighted that when the mother is educated, this means higher income and more health awareness and ability to help throughout child life (Saunders, et al., 2014) stated that when mother' education decreases, the health risk to herself and to her children and family also increase. Also agreement with this, (Hallman, 2012). emphasized that the educated mother are able to take care of their children, especially the $\mathrm{CP}$ children who need more care and understanding of their needs and problems. More than quarter of them were housewife also less than one quarter of them were working mothers.

Regarding crowding Index, it was found more than half of mothers were living in crowded housing condition .This factor can contributed to less of care to their children.As regard of income of studied mothers ,more than three quarter of them had insufficient income ,also reported that there was significantly positive relation between mothers' income and level of dependency of their children. Badawi, and Blair, (2013) who reported positive correlation between the decreasing socioeconomic class and the severity of disability and nutritional impairment in $\mathrm{CP}$ children, (Adam et al,2010) who stated when unemployment is high and/or the economy is unstable and there also may be less inclination to financially subsidize those who are disabled. There was most of parent hassles within family, people or institution to get financial help and feeling of burden with shortage of financial resources. This finding is supported by Nelson, (2013), who reported that most families find that expensive essentials are needed to care for, manage, or treat a child with $\mathrm{CP}$ and also found most families have ongoing, extra, out of pocket expenses that create problems for other family expenses. Although insurance, public programs and covered services are of help, they require time to access and have frustrations of their own.

Regarding perceived causes of disease during pregnancy and labor,more than half of mothers had natal causes this is confirmed with Novak,(2011)who pointed out that the dyskinetic syndromes are most likely to occur with perinatal risk factors such as asphyxia was also supported by Bersani, (2012) that the form of $\mathrm{CP}$ most often associated with birth asphyxia. Novak,(2011) stated that the most serious risk factors are marked immaturity and sever birth asphyxia.

As regards characteristics of children with $\mathrm{CP}$, it was found that their mean age was $4.5 \pm 0.5$ where more than third aged 3 years; there was a relation between children' age and their dependency level where more than two third of children become partial dependent post program who aged from 4 to less than 5 years, also nearly two third of them were boys, this is in accordance with Kolawole (2014) who mentioned that $\mathrm{CP}$ occurs more frequently in males than females, however, this was contradicting with Butler, (2014) who stated that $\mathrm{CP}$ occur in both sex equally. 
Regarding child's rank order, it was found more than one third of studied children in this study were ranked as the third in their families, this could be due to the lack of mother tendency toward prenatal, perinatal and postnatal follow up especially in low socioeconomic status. As regards types of $\mathrm{CP}$ the majority $(58.1 \%)$ were spastic type this agreement with Lindeman, et al 2010) who reported that children with spastic diplegia have the higher incidence. Slaman, (2010) who mentioned that most $(77.4 \%)$ of the children identified with $\mathrm{CP}$ had spastic CP. Regarding child' associated problems (severity of disease), it was found that the majority had mild \&moderate $\mathrm{CP}(58.1 \%)$, $(30.6 \%)$ respectively, there was a relation between children' associated problems and their dependency level pre and post program.

\section{Second part :- assessment and evaluation of mothers' level of knowledge}

The following part of discussion focuses on the assessment and evaluation of total mothers' level of knowledge regarding to care for their children with cerebral palsy (pre ,post and 3 month after the program implementation).the present study results Showed that, after program implementation, mothers had higher good score level than pre and follow up after program implementation, which highlights on the positive effect of intervention program on mothers' knowledge. This finding is in agreement with Ahmed, and Youssef, (2013), who emphasized that the highest percentage of mothers' knowledge were un-satisfactory before implementation of the guidelines which improved immediately after implementation of the guidelines, this level of knowledge was decreased but still better than before i.e. follow up.
Third part: assessment and evaluation of mothers' level of practice:

Comparison of total score level of mothers' practice pre, post and follow up after program the present study results showed that, after program implementation, mothers were done correctly than pre and follow-up after program implementation results highlighted the positive effect of intervention program on mothers' practice. Ones (2011), who stated that it is difficult for the intellectual capacity of illiterate mothers to retain practical knowledge in their memory for long time without reinforcement,.

The Fourth part, discussion focuses on the statistical relations.

\section{A-Correlation between mothers' knowledge and their practice:}

Regarding to relation between mothers' knowledge and their practice, this study result showed that statistical significant positive relations were detected between them related to all items.

B-Correlation between associated problems of children and score total level of mothers' knowledge:

The present study showed that statistical significant relations between associated problems of children and level of mothers' knowledge

C-Correlation between associated problems of children and total score level of mothers' practices:

Considering the relation between associated problems of children and level of mothers' practices The present study showed that statistical significant 
relations between associated problems of and total score level of mothers' practices

In summary our study finding revealed that program was affected in improving daily activities of children with CP namely their feeding, drinking, dressing, transferring, elimination skill and grooming (personal hygiene). Mothers and their children are in need for continuous training about activity of daily living of their children.

Therefore, increasing mothers' knowledge would certainly lead to improvement in their practice, their awareness about needs of children with $\mathrm{CP}$ and in child' independence in ADLs. This analysis confirm that the intervention program had appositive impact on mothers' knowledge which was positively reflected on their practice ,and their awareness about their children' needs. The outcome was a better self care competencies among their children who become more independent in their daily living activities.

On summary the results of this study support the hypothesis that intervention program will improve some factors might affect on level of mother's knowledge and practices also, dependency level of their children.

\section{Conclusion:}

Improvement in the level of mother's knowledge and practices also, dependency level of their children as compared to pre implementation of the intervention program.

\section{Recommendation:}

1-Intervention sessions should be provided for mothers of cerebral palsy children about care of their children, as well as, community resources from whom they may seek assistance and support to fulfill with all activities of daily living (dependency level) of their CP child.

2-Improving mothers 'knowledge toward the importance of pre, perinatal, and post natal follow up

3-Increase the public a awareness toward care of child and available specialty center that provide care for these children through mass media such as television, pamphlets, and posters.

\section{References:-}

Adam T., Juan C. Gallegos, Kevin J. Gertz, Joyce M. (2010): "Symptom Burden in Individuals with Cerebral Palsy." Journal of Rehabilitation Research \& Development 47.9.

Ahmed, F. and Youssef, M. (2013): Stressors Facing Mothers of Children with Cerebral Palsy *Med. J. Cairo Univ., Vol. 81, No. 1, December: 1099-1104,

www.medicaljournalofcairouniversity. net The Department of Pediatric Nursing, Faculty of Nursing, Suez Canal and Zagazig Universities.

Badawi, N;\& Blair, E. (2013): "A systematic review of risk factors for cerebral palsy in children born at term in developed countries.". Developmental medicine and child neurology 55 (6): 499-508.

Bersani, I; Thomas, W; Speer, CP. (2012). "Chorioamnionitis--the good or the evil for neonatal outcome?". The journal of maternal-fetal \& neonatal medicine : the official journal of the European Association of Perinatal Medicine, the Federation of Asia and Oceania Perinatal 
Societies, the International Society of Perinatal Obstetricians. 25 Suppl 1: 12-6.

Butler, A. and Alexander, G. (2014): Preterm Birth: Causes, Consequences, and Prevention. Institute of Medicine Committee on Understanding Premature Birth and Assuring Healthy Outcomes. National Academies Press. Washington, DC, 1104 Stressors Facing Mothers of Children with Cerebral Palsy.

Gulanick,M.,\&Myers,J.(2016): Nursing care plans $\left(7^{\text {th }}\right.$ ed $)$. United state of America, Elsevier mosby,p.p212-213.

Hallman, M. (2012): "Premature birth and diseases in premature infants: common genetic background?". The journal of maternal-fetal \& neonatal medicine : the official journal of the European Association of Perinatal Medicine, the Federation of Asia and Oceania Perinatal Societies, the International Society of Perinatal Obstetricians. 25 Suppl 1: 21-4

Klingels, K.; Molenaers, G.; Desloovere, K.; (2011): "Upper limb motor and sensory impairments in children with hemiplegic cerebral palsy. Can they be measured reliably?". Disability \& Rehabilitation 32 (5): 409-416.

Kolawole TM, Patel PJ, Mahdi AH (2014): "Computed tomographic (CT) scans in cerebral palsy (CP)". Pediatr Radiol 20 (1-2): 23-27.

Lindeman E, van Wely L, Becher JG, Reinders-Messelink HA, Verschuren O, (2010): a randomized controlled trial on the effects of a physical activity stimulation program in children with cerebral palsy. BMC Pediatrics p.523
Martin, J. (2016): Handbook of practice nursing (3rd ed).London: Churchill Livingstone Co., pp.9-10.

MC-Court, B., (2015): Neurology. In spinally practice of rehabilitation nursing, $3^{\text {rd }}$ ed. brookes publishing co., Tokyo, PP. $46-60$.

Nelson, KB (2013). "The association of cerebral palsy with birth asphyxia: a definitional quagmire.". Developmental medicine and child neurology 55 (3): 210-6

Novak, I ; McIntyre, S; Morgan, C; Walker, K; (2011): "Cerebral palsy-don't delay.". Developmental disabilities research reviews 17 (2): 114-29.

Ones K., (2011: Assessment of the quality of life of mothers of children with cerebral palsy primary caregivers, Neuro-rehabilitation and Neural. Repair., 19 (3): 232-240.

Saunders, NR; Hellmann, J; Farine, D. (2014): "Cerebral palsy and assisted conception.". Journal of obstetrics and gynaecology Canada: JOGC = Journal d'obstetrique et gynecologie du Canada : JOGC 33 (10): 1038-43.

Sawatzky,R.,(2015):Physical activity as a mediator of the impact of chronic conditions on quality of the life in older adults.Available at:htt://www.hqlo.com. (accessed January 2015)

Shahim, M., (2014): Correlations between parents and teachers' ratings of social skills for a group of developmentally disabled children in Iran, 84(3): 853 865.

Slaman J, (2010): Effectiveness of an intervention to stimulate physical 
activity and improve physical fitness of adolescents and young adults with spastic cerebral palsy; a randomized controlled trial. BMC Pediatrics p.6

Stenvenson, A., (2016): "Clinical correlates of linear growth in children with cerebral palsy" Dev. Med. child Neurol, PP. 35: 124 - 132.

Winder, S., (2013): Review of cerebral palsy: part II: Identification and Intervention; Neo natal Network, 16 (4): $18-28$.
World Health Organization Department of health statistics and information, Evidence and Research Cluster (2011): The global burden of disease, update. Geneva: WHO.

Zerai,A., \& Gilanian,M. (2015): Selfeffecacyas a function of Language Learning strategy use, British Journal of Education .Society\& Behavioural Science;9(3):211-212. 